\title{
Proceedings of the Human Factors and Ergonomics Society Annual Meeting \\ http://pro.sagepub.com/
}

\section{Is Human Reliability Relevant to Human Factors?}

Ronald L. Boring, Emilie Roth, Oliver Straeter, Karin Laumann, Harold S. Blackman, Johanna Oxstrand and Julius J.

Persensky

Proceedings of the Human Factors and Ergonomics Society Annual Meeting 2009 53: 610

DOI: $10.1177 / 154193120905301006$

The online version of this article can be found at:

http://pro.sagepub.com/content/53/10/610

\section{Published by:}

(9)SAGE

http://www.sagepublications.com

On behalf of:

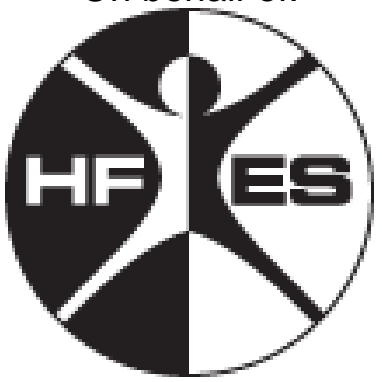

Human Factors and Ergonomics Society

Additional services and information for Proceedings of the Human Factors and Ergonomics Society Annual Meeting can be found at:

Email Alerts: http://pro.sagepub.com/cgi/alerts

Subscriptions: http://pro.sagepub.com/subscriptions

Reprints: http://www.sagepub.com/journalsReprints.nav

Permissions: http://www.sagepub.com/journalsPermissions.nav

Citations: http://pro.sagepub.com/content/53/10/610.refs.html

>> Version of Record - Oct 1, 2009

What is This? 


\title{
IS HUMAN RELIABILITY RELEVANT TO HUMAN FACTORS?
}

\author{
Ronald L. Boring, ${ }^{1}$ Emilie Roth, ${ }^{2}$ Oliver Straeter, ${ }^{3}$ Karin Laumann, ${ }^{4}$ \\ Harold S. Blackman, ${ }^{5}$ Johanna Oxstrand, ${ }^{6}$ Julius J. Persensky ${ }^{7}$ \\ ${ }^{1}$ Sandia National Laboratories, ${ }^{*}$ Albuquerque, New Mexico, USA \\ ${ }^{2}$ Roth Cognitive Engineering, Brookline, Massachusetts, USA \\ ${ }^{3}$ Universität Kassel, Kassel, Germany \\ ${ }^{4}$ Norwegian University of Science and Technology, Trondheim, Norway \\ ${ }^{5}$ Center for Advanced Energy Studies, Idaho National Laboratory, Idaho Falls, Idaho, USA \\ ${ }^{6}$ Vattenfall Ringhals AB, Väröbacka, Sweden \\ ${ }^{7}$ US Nuclear Regulatory Commission, Washington, DC, USA
}

\begin{abstract}
This paper presents a number of views from a panel discussion on the relationship between human reliability analysis (HRA) and human factors. HRA emerged concurrently with the field of human factors and now features a nearly fifty-year shared history. While built on human factors, HRA distinguished itself early on from human factors due to its emphasis on predicting human performance. While one of the major focus areas of human factors has been improving the design of novel systems to optimize human performance, HRA has largely focused on predicting human performance for as-built systems. Over time, as HRA became closely tied particularly to the nuclear energy industry, it increasingly became a field associated more with reliability engineering than human factors. Yet, the similarity to human factors has not abated, nor has the opportunity for the two fields to cooperate. Human factors research provides the empirical basis to support predicting human performance in HRA. Importantly, HRA continues to benefit human factors by providing: (1) a framework for modeling human performance, (2) an example of how a human factors discipline can be seamlessly integrated with an engineering field, and (3) insights on how predictive modeling may be used as a system design tool.
\end{abstract}

\section{INTRODUCTION}

At the Sixth Annual Meeting of the Human Factors Society, November 28-30, 1962, a symposium was held on the topic of "Human Error Quantification" (Swain, Altman, and Rook, 1963). This meeting introduced an early version of the Technique for Human Error Rate Prediction (THERP), the first formal method for human reliability analysis (HRA). The precepts of HRA have remained largely unchanged: HRA seeks to identify sources of human error (although the term human error has since come to be viewed negatively) and quantify the likelihood of such errors (Boring, 2009; Sheridan, 2008). Importantly, the 1962 symposium established a research agenda for HRA, including the collection of empirical data from human factors studies to inform the ability of HRA to predict human performance.

Early HRA emerged amid weapons reliability efforts in the 1950s (Meister, 1999). Subsequent to the 1962 symposium, human factors forums were the preferred venue for HRA research, and there was a healthy interplay between research in the two closely related fields. The predictive nature of HRA was noted as being somewhat at odds with conventional thinking in human factors (Swain, Altman, and Rook, 1963). Conventional human factors research centered strongly on system design and system improvement to optimize human performance. Because the evaluation of human performance for the purposes of system design

${ }^{*}$ Sandia is a multiprogram laboratory operated by Sandia Corporation, a Lockheed Martin Company, for the United States Department of Energy under contract DE-AC04-94AL85000. collects data for specific system tasks, a comprehensive collection of empirical data was not available to document human performance. Thus, HRA required a fair amount of generalization of those data that were available. This approach challenged assumptions about the external validity of psychological findings, by using available human performance data in ways for which they were not intended. Still, the approach held merit, and the gradual accumulation of human performance data allowed HRA to make plausible and valid predictions about human errors.

Meister notes that the ability to predict is one of the hallmarks of science, and HRA uniquely filled that role within human factors (1999). HRA effectively set the stage for other predictive endeavors in human factors - namely, human performance modeling, cognitive modeling, and artificial intelligence techniques - that chronologically followed HRA. This lineage is clearly evident in the topical coverage of THERP, which more closely resembled the emerging cognitive movement than the then dominant behaviorist movement in psychology.

HRA has continued to evolve in methods and applications since the first versions of THERP. THERP was applied to the domain of nuclear power plants (Swain, 1969). Subsequent to the Three Mile Island nuclear power plant meltdown in the US in 1979 (Osif, Baratta, and Conkling, 2004), a refined version of THERP (Swain and Guttman, 1983) became a cornerstone of plant safety assurance and risk-informed decision making by the US Nuclear 
Regulatory Commission. HRA was subsequently adopted widely across the international nuclear industry, where HRA became an important component of probabilistic risk assessment (PRA), combining hardware and human reliability into plant system models (Gertman and Blackman, 1994).

A recent review (Bell and Holroyd, 2009) identifies 39 distinct HRA methods. Additional HRA methods are identified in other reviews (e.g., Adhikari et al., 2008; Forester et al., 2006; Lois et al., 2008). Early HRA methods are sometimes called first-generation methods. Newer, socalled second-generation methods feature a greater emphasis on cognition, context, and errors of commission (Boring, 2007). Recent research efforts to use cognitive modeling for HRA (e.g., Laux and Plott, 2007), have been labeled thirdgeneration methods. The semantics of such labels are not as important as the evolution of the methods. HRA methods continue to become more refined and more usable, and they address increasingly nuanced aspects of human performance. While the majority of HRA methods continue to support the nuclear industry, new methods are being applied to other safety-critical domains such as the automotive sector (Sträter, 2000), the oil industry (Aven, Sklet, and Vinnem, 2006), and air-traffic control (Kirwan and Gibson, 2007).

Importantly to the human factors community, HRA has become closely linked with reliability engineering. The result of this alignment is that many of the advances in HRA are disseminated outside the mainstream human factors publication channels. A major paper in HRA is more likely to appear in the journal Reliability Engineering and System Safety than in Human Factors. Late-breaking research more frequently appears at American Nuclear Society conferences than at the annual meetings of the Human Factors and Ergonomics Society.

HRA has become seamlessly integrated in the safety engineering domains it supports. But, HRA as a field must be careful not to distance itself from its human factors roots. The quality of HRA depends on human performance insights, and these insights are most readily built on a human factors foundation. Moreover, recent work using HRA for human performance modeling (Laux and Plott, 2007) and HRA for design (Stanton and Baber, 2002) suggests that the benefit is reciprocal. Human factors stands much to gain still from HRA, just as HRA depends on human factors for improved insights on human performance.

While HRA represents nearly 50 years of research on human performance, how has it come to pass that the field is now little known within human factors? Is HRA a model for how human factors disciplines can become fully integrated into engineering disciplines? Has HRA moved too far afield from human factors to be considered a human factors discipline? Is HRA still relevant to human factors? To answer these questions, the proposed panel brings together practitioners and researchers from both HRA and human factors. The goal of the panel is to discuss the intersection of HRA and human factors from a diverse range of perspectives.

\section{PANELIST POSITION STATEMENTS}

Informing HRA with Human Factors-Emilie Roth

HRA and risk assessment methods have proved to be important tools for informing design and regulation of new systems. While HRA made its first inroads in the nuclear power generation industry, it has come to be adopted and relied on by vendors, operators and regulators of complex high risk systems in a broad range of domains. For example, risk analysis methods are used to establish the safety of new medical devices (Israelski and Muto, 2006). Risk analysis and HRA methods are also being used by the Federal Railroad Administration to assess the safety of new train control technologies (Wreathall et al., 2004). The importance of risk-based methods in informing system design was explicitly recognized by the recent National Research Council committee on human-system design. Risk analysis methods were prominently featured as important evaluation tools for Human System Integration (Pew and Mavor, 2007).

Human Factors can contribute to both the practice of HRA and its research foundations. Risk analysts generally acknowledge that the value of risk analysis and HRA come not from the particular probability values that are produced, but from the insights gained with respect to sources of vulnerability and risk from the analysis process itself. Human Factors specialists can effectively contribute to those domain and human performance analyses.

For example, I recently partnered with human reliability analysts (who now tend to come from engineering disciplines) to uncover important human performance issues associated with the introduction of new train control technologies. Human reliability modeling and quantification methods were then used to assess the overall impact on safety (Wreathall et al., 2004).

There is also substantial room for human factors to contribute to the science base from which firmer predictions of human performance (and human performance quantification) can be drawn. One emerging research area is resilience engineering (Hollnagel, Woods, and Levenson, 2006). While HRA has traditionally focused on prediction of human error, there is a growing movement within both the HRA and human factors communities to examine the role of humans in contributing to safer, more resilient systems. There is a need for more research to understand how individuals and teams contribute to system resilience and how new technologies can be deployed to enhance this role.

\section{Usability is Not Safety-Oliver Straeter}

Many activities are currently on the way to better including human factors in system design in order to increase safety. In particular, there is a hope that this might strengthen the concept and design phase and will lower the risk of safety issues in the implementation and operation of a system. Yet, there is no one-to-one relation of human factors to safety and the inclusion of human performance into safety as proposed by HRA. One cannot conclude that, if a system is poorly designed ergonomically (or cognitively), then it is 
unsafe. Certain maintenance tasks, for instance, are made cumbersome (badly designed from a general human factors point of view) just to make them safer (more robust against skill based errors). As another example, the cognitive task analysis of a launch system of a nuclear missile would reveal a relatively easy ergonomic solution if one focused on the usability objective. The system would simply have a big red button to push. However, an ergonomically well designed system would not deliver the required safety performance. Hence the task is made deliberately cumbersome, with several checks and interlocks and control mechanisms by several persons.

Subsuming such examples, a precondition for a successful differentiation of human factors and human reliability needs to accept that human factors does not contribute to safety per se. Differentiation is required before integration. This implies a clear layered approach of the different human factors objectives and how they contribute to the overall safety of the system. Methods not clearly differentiating the objectives or not clearly specifying how a particular human factors objective serves safety deliver unsuitable tools from a safety point of view.

Another point often discussed as a difference is that human factors is seen as purely qualitative and HRA as purely quantitative. This fallacy is often taken as the argument against HRA. "We are not able to assess human performance quantitatively" is the usual counterargument. However, looking into statistical methods and approaches used in human factors and HRA, both are qualitative and both are quantitative. This argument reveals an arbitrary difference between both.

What we need to do is to get both processes interacting better. The methodological commonalties might serve as a good basis to achieve a better integration of both human factors and HRA.

\section{Using HRA and Human Factors for Error Reduction-Karin Laumann}

HRA and human factors are related research areas. In any project to develop quantitative risk analysis and error reduction suggestions for a new industry, research from both fields is necessary. Knowledge from both HRA and human factors should be used in the same research project.

There is an ongoing research project called Risk OMT (Vinnem, 2008) working on further developing a method for quantitative risk analysis in the Norwegian offshore oil and gas installations. This method is called Barrier and Operational Risk Analysis (BORA). Descriptions of this method can be found in Aven, Hauge, Sklet, and Vinnem (2006); Aven, Sklet, and Vinnem, (2006); Haugen, Seljelid, Sklet, and Vinnem, (2007); Sklet, Aven, Hauge, and Vinnem, (2006). BORA is a quantitative and qualitative analysis method and includes both pre initiating events (events that cause a reduced performance of a barrier before an accident has occurred, or events causing an accident to occur) and post initiating events (events that affect a barrier after an accident has occurred). BORA includes an analysis of both hardware and human factors conditions. The part of BORA that analyzes human factors conditions is similar to HRA methods like THERP in that performance shaping factors are used to assess the likelihood of human errors.

One of the main goals of BORA is to use the analysis for error reduction, which is the focus of current research. In an HRA, the likelihood of human error is calculated from the expected effects of performance shaping factors. A very reasonable argument could be that if an HRA really measures the factors that are most likely to affect human performance, then this analysis could be used to identify factors that should be changed in order to decrease the likelihood of human errors. Other methods from human factors are also needed to analyze how the performance shaping factors should be changed.

However, an important question is: "Does HRA really capture the most important factors that affect the likelihood for human failure or success?" This question has been very difficult to answer in HRA because of a lack of data. The events most often analyzed in HRA, e.g., in the nuclear power industry, happen so infrequently that it is impossible to actually validate the likelihoods found in an HRA against existing data. Up to now, HRA has almost exclusively analyzed post initiating events, which are events that happen very infrequently. BORA also includes an analysis of pre initiating events. If HRA starts to analyze pre initiating events, which happen more frequently, it might be possible to test how well HRA predicts the likelihood of human failures. It could also be possible to test if changing the factors found to be most likely to cause human errors actually reduces the likelihood for those errors to occur.

HRA is a Tool for Human Factors-Harold Blackman

The development of human reliability techniques has been based upon the discipline of human factors from its inception. Historically, methods were developed upon task analysis, quantification of individual differences and performance, and interpretation of human performance characteristics in order to estimate the impact of humans in the success of human-machine systems. Data have been collected across a variety of domains, including manufacturing, nuclear power, and process control industries. Concepts and data from the general human factors literature concerning areas such as stress, training, workload, complexity, and context have all made their way into the numerous HRA methods that have been developed. Next generation HRA techniques have really adopted the more sophisticated techniques of cognitive task analysis, as well as principles of resilient engineering.

There can be no doubt as to the relevancy of HRA to human factors. It is a principal way that the impact of the human is determined in a variety of high risk industries including, at a minimum, space and nuclear power. The tools can help to determine the impact of changes to the human system and its overall impact on mission success. It is a way to open doors for the human factors professional to 
impact design and management of human systems on a dayto-day basis. Without such tools, our human factors profession may not have the ability to enter into the conversation to improve safety in high risk industries.

\section{A Swedish Human Factors Journey-Johanna Oxstrand}

The Swedish nuclear industry is facing an exciting era. The goal is to reach world class safety in a few years. One step on the path to reach world class safety is to review the way we work with human factors. In the Swedish nuclear industry, human factors work has traditionally been spread throughout the organization, and there has been no coordination between the different activities. Reactive investigations, human-computer interaction ( $\mathrm{HCI})$ analyses, and HRAs are some examples of these different activities. It is costly for the organization since it takes a lot of resources (time, money, and people) and there is no guarantee that all aspects are covered in the end, nor that duplicate efforts have been avoided. To illustrate these points, my contribution to the panel is the human factors journey for one of the Swedish nuclear plants.

Yesterday. The Human Factors group was mainly conducting reactive investigations, i.e., trying to find the root cause for an event where humans had been involved. In addition to the human factors investigations, there was also HRA and HCI work conducted in the organization. Both the HRA and the HCI work were conducted far from the Human Factors group. HRA existed only in the PRAs and was coordinated by the PRA group. Vendors conducted the HRA, and the main focus of the HRA was the human error probability (HEP). The qualitative part of the HRA was discarded as soon as the HEP was produced. The HCI work was part of all major design projects. The organization only had a single coordinator who was in charge of all contacts with the vendor who conducted the analyses. None of the three fields communicated with each other. There was no knowledge about which analyses had been conducted, what the results or findings were, and which analyses were to be conducted.

Today. The nuclear plant decided to reorganize and moved the Human Factors group, the HRA competence, and the HCI competence to one group along with people working with operational experience and human performance tools. The purpose of this new group is to increase the synergies between the different fields. In the field of human factors, the focus has started to shift toward proactive analyses. The HRA methodology is mainly proactive, and there are many different HRA methods to choose from. This makes the HRA competence a useful toolbox when developing a "new" way to conduct human factors analyses at the plant. HRA is still heavily tied to the PRA. There is still almost no communication between the different fields regarding results and findings. There is a need for some kind of protocol or guideline to make this start and to make it last.

Tomorrow. There will be more collaboration between the different fields and the development of fields will accelerate because of this. Reports from observations and near misses will be reviewed in order to find patterns and trends. These patterns will indicate where to direct proactive analyses. The department will have to initiate the analysis since they are the ones who found the patterns. The different analysis results and findings will be packaged in a way that could be useful as input for future analysis. PRA is starting to use the qualitative part of the HRA in the final report, and this qualitative part is also communicated to the rest of the human factors field in the organization.

Long Term. The fields are merged into one unified Human Factors organization, which communicates results and findings as well as planned analyses. The organization itself-not just external stakeholders - initiates proactive analyses that human factors, HRA, and HCI staff will jointly support. The methodology used for an analysis depends on the purpose instead of artificial domain boundaries. The amount of resources spent on analyses will decrease, since the number of investigations has decreased, the amount of duplicate effort has decreased, and the organization has a much greater and more effective focus on safety than before.

\section{Still Ahead for Human Factors and HRA-J. Persensky}

While human factors helps identify human performance issues, HRA can help to prioritize human factors issues based on risk. However, in many cases, HRA is not mature enough as a field to provide robust prioritization of issues. For example, within the nuclear power industry, there are extensive lists of human factors issues (e.g., O'Hara, et al., 2008), but there are no attempts to explain which of these issues is the most important in terms of risk. HRA has not to date been effective in prioritizing such lists of human factors issues. The lists could be substantially shorter if we better understood how certain actions had effects on plant risk. Consequently, licensees and vendors are being required to address things like the font size on screens, when we don't really know if the specific font size is risk significant. Other issues in human factors that are known to have a big impact on plant safety, like fatigue and safety culture, are not yet adequately addressed by HRA methods.

Human factors research should be used to provide data for HRA. Yet, there is tremendous cost associated with collecting original data or even reprocessing existing data for use in quantifying HRA. This has admittedly not been a focus at the US Nuclear Regulatory Commission, partially because we don't understand the best way to do this. HRA has not provided a clear prescription for human factors on what data are needed. What values are needed under what conditions? Moreover, HRA deals with extremely small probabilities of human actions, which can be extremely difficult to observe in human factors studies. To observe such low frequency human errors, it is necessary to run many more human participants in studies or to run them longer than we have in the past. Clear guidance on HRA data gathering requirements would facilitate research that is more attuned to helping HRA methods develop empirically driven HEPs. 


\section{REFERENCES}

Adhikari, S., Bayley, C., Bedford, T., Busby, J., Cliffe, A., Devgun, G., Eid, M., French, S., Keshvala, R., Pollard, S., Soane, E., Tracy, D., \& Wu, S. (2008). Human reliability analysis: A review and critique. Final Report for EP/E017800/1. UK Engineering and Physical Sciences Research Council.

Bell, J., \& Holroyd, J. (2009). Review of human reliability assessment methods, RR679. Buxton, UK: Health and Safety Executive.

Aven, T., Hauge, S., Sklet, S., \& Vinnem, J.E. (2006). Methodology for incorporating human and organizational factors in risk analysis for offshore installation. International Journal of Materials \& Structural Reliability, 4, 1-14.

Aven, T., Sklet, S., \& Vinnem, J.E. (2006). Barrier and operational risk analysis of hydrocarbon releases (BORARelease), Part I. Method description. Journal of Hazardous Materials, A137, 681-691.

Boring, R.L. (2009). Human reliability analysis in cognitive engineering and system design. Frontiers of Engineering: Reports on Leading-Edge Engineering from the 2008 Symposium (pp. 103-110). Washington, DC: National Academy of Engineering.

Boring, R.L. (2007). Dynamic human reliability analysis: Benefits and challenges of simulating human performance. In T. Aven \& J.E. Vinnem (Eds.), Risk, Reliability and Societal Safety, Volume 2: Thematic Topics. Proceedings of the European Safety and Reliability Conference (ESREL 2007) (pp. 1043-1049). London: Taylor \& Francis.

Forester, J., Kolaczkowski, A., Lois, E., \& Kelly, D. (2006). Evaluation of human reliability analysis methods against good practices, NUREG-1842. Washington, DC: US Nuclear Regulatory Commission.

Gertman, D.I., \& Blackman, H.S. (1994). Human reliability \& safety analysis data handbook. New York: WileyInterscience.

Haugen, S., Seljelid, J., Sklet, S., \& Vinnem, J.E. (2007). Operational risk analysis. Total analysis of physical and non-physical barriers. H3.1 Generalisation report. Rev 1.

Hollnagel, E., Woods, D.D., \& Levenson, N. (2006). Resilience engineering: Concepts and precepts.

Burlington, VT: Ashgate.

Israelski, E.W., \& Muto, W.H. (2006). Human factors engineering and the design risk management in medical devices. In P. Carayon (Ed.), Handbook of human factors and ergonomics in healthcare and patient safety (Part V, Technology). Mahwah, NJ: Erlbaum.

Kirwan, B., \& Gibson, H. (2007). CARA: A human reliability assessment tool for air traffic safety management-Technical basis and preliminary architecture. In F. Redmill and T. Anderson (Eds.), The Safety of Systems: Proceedings of the Fifteenth SafetyCritical Systems Symposium (pp. 197-214). London: Springer Verlag.
Laux, L., \& Plott, C. (2007). Using operator workload data to inform human reliability analyses. Official Proceedings of the Joint 8th IEEE Conference on Human Factors and Power Plants and the 13th Annual Workshop on Human Performance/Root Cause/Trending/Operating Experiencel Self Assessment, 309-313.

Lois, E., Dang, V.N., Forest, J., Broberg, H., Massaiu, S., Hildebrandt, M., Braarud, P.Ø., Parry, G., Julius, J., Boring, R., Männistö, I., \& Bye, A. (2008). International HRA empirical study-Pilot phase report, HWR-844. Halden, Norway: OECD Halden Reactor Project.

Meister, D. (1999). The history of human factors and ergonomics. Mahwah, NJ: Lawrence Erlbaum Associates.

O'Hara, J., Higgins, J., Brown, W., Fink, R., Persensky, J., Lewis, P., \& Kramer, J. (2008). Human factors considerations with respect to emerging technology in nuclear power plants, NUREG/CR-6947. Washington, DC: US Nuclear Regulatory Commission.

Osif, B.A., Baratta, A.J., \& Conkling, T.W. (2004). TMI 25 years later: The Three Mile Island nuclear power plant accident and its impact. University Park, PA: Pennsylvania State University Press.

Pew, R.W. \& Mavor, A.S. (2007). Human-System Integration in the System Development Process: A New Look. Washington, DC: The National Academies Press.

Sheridan, T.B. (2008). Risk, human error, and system resilience: Fundamental ideas. Human Factors, 50, 418426.

Sklet, S., Vinnem, J.E. \& Aven, T. (2006). Barrier and operational risk analysis of hydrocarbon releases (BORARelease). Part 2: Results from a case study. Journal of Hazardous Materials, A137, 692-708.

Stanton, N.A., \& Baber, C. (2002). Error by design: methods for predicting device usability. Design Studies, 23, 364384.

Sträter, O. (2000). Evaluation of human reliability on the basis of operational experience, GRS-170. Cologne: Gesellschaft für Anlagen- und Reaktorsicherheit (GRS) $\mathrm{mbH}$.

Swain, A.D. (1969). Human reliability assessment in nuclear reactor plants, SC-R-69-1236. Albuquerque: Sandia Laboratories.

Swain, A.D., Altman, J.W., \& Rook, L.W., Jr. (1963). Human error quantification. A symposium. SCR-610. Albuquerque: Sandia Corporation.

Swain, A.D., \& Guttman, H.E. (1983). Handbook of human reliability analysis with emphasis on nuclear power plant applications, Final report, NUREG/CR-1278. Washington, DC: US Nuclear Regulatory Commission.

Vinnem, J.E. (2008). On the risk to personnel in the offshore industry. Conference Proceedings of PSAM9.

Wreathall, J., Bley, D., Roth, E., Multer, J. \& Raslear, T. (2004). Using an integrated process of data and modeling in HRA. Reliability Engineering and System Safety, 83, 221-228. 